\title{
Careers at Biotech Start-Ups and in Entrepreneurship
}

\author{
Susan Froshauer \\ Connecticut United for Research Excellence, Inc., New Haven, Connecticut 06510 and CURE Innovations \\ Commons, Groton, Connecticut 06340 \\ Correspondence: froshauer@gmail.com
}

\begin{abstract}
The world of biotechnology "start-ups" and entrepreneurship offers exciting new avenues for driving state-of-the-art research using an arsenal of multidisciplinary skills, whether your role is as part of a team or as a leader. Although traditionally these positions may not be as secure as those offered by some of the larger companies, the small start-up culture provides opportunities for contributing at many levels to a wide range of responsibilities: from scientific discovery to delivery of proof of concept and intellectual property; from analysis of market opportunities and competitive intelligence to creation of time lines and business plans for a first product. Often, if you get in on the ground level, you get to validate your own concept, pitch to potential investors, argue value, build a team, engage advisors, and then, with funding in hand, launch an entirely new research and development (R\&D) enterprise. Many of the skills and much of the experience gained while pursuing a graduate degree can be put to good use in these arenas as well. This path, however, is not for the faint of heart; it requires not only a strong scientific background and organizational skills, but also the ability to work well on a team, excellent communication skills, and persistence when faced with delays or disappointment. With increasing responsibilities in the small company come the requirements for aptitudes for leadership, strategic and financial planning, networking, negotiating, and managing both projects and personnel.
\end{abstract}

eaving the relatively well-defined, safe path Lof research at an academic or established biotechnology/pharmaceutical institution for a new venture can be risky but also highly challenging and rewarding. In contrast to the more narrow focus of academia, in which often the organizing principle is to contribute basic research and fundamental understanding, the clear goal in the start-up setting is to develop an application, service, or product that has value medically and commercially. It is not sufficient to simply have a clever research idea for a new product. As a member of a team, you also consider how your research/product will be differentiated, the cost and time needed to deliver it, prospects for patenting, and regulatory hurdles.

The realm and the role of the bioscience sector are rapidly changing, creating new opportunities for small start-ups and biotechs. In particular, as large pharmaceutical companies downsize their R\&D workforce in response to pricing and regulatory pressures, they seek to invest in and/or acquire smaller companies and focus their efforts on product marketing, sales, and distribution. For example, to bolster its pipeline, Cubist acquired Trius and Optimer, smaller companies with antibiotic products, and Merck has taken over Idenix (admittedly

Editors: Kaaren Janssen and Richard Sever

Additional Perspectives on Career Options for Biomedical Scientists available at www.cshperspectives.org

Copyright (C) 2017 Cold Spring Harbor Laboratory Press; all rights reserved

Cite this article as Cold Spring Harb Perspect Biol 9: a032938 


\section{S. Froshauer}

no longer a "small" biotech company, but the model holds). For many of these large pharmaceutical companies, acquiring smaller or startup biotechnology companies provides support for their own development efforts as their older products lose patent protection. Another corporate strategy is to move the research efforts from the company $\mathrm{R} \& \mathrm{D}$ departments into academic settings; this shift in investment is thought to be both more efficient and less expensive for the companies. In this model, generating and exploring new ideas and innovative concepts is assumed by laboratories in the universities, whereas the companies focus their attention on funding and supporting clinical trials and other developments. Principal investigators-either individually or in collaboration with colleagues-have formed small satellite companies on the basis of an idea or finding coming out of their laboratories (or sometimes coming from conversations with like-minded colleagues). Universities such as Yale and the University of Connecticut are also producing their own companies to meet the demands for healthcare information technology or advances in personalized medicine. Cutbacks in federal funding also kindle a start-up culture, as faculty spin out their very early technology to access different types of federal funding, such as small business grants.

Generally, start-up companies are where the perhaps risky but truly innovative experimen- tal efforts are carried out. If your experience, vision, and personality are well suited to tolerating the possible lack of stability, these environments can provide a challenging and exciting career. The outlook for the small biotech company is also favorable, with biotech stocks outperforming the general market. And, according to market analysts, the increase in initial public offerings (IPOs) by start-ups in the biotech sector seems likely to continue. Clearly, the need for innovation in research is continuously expanding and is being met by a variety of original and imaginative approaches.

\section{JOBS}

We first discuss the positions likely to be found at a small start-up because this may be your starting point, allowing you to have the opportunity to gain experience in the running of a small company. This experience will serve you well, especially if you wish to consider launching your own venture.

\section{Working in a Small Biotech Company}

In an existing small start-up company, the positions will vary, depending on the maturity and the nature of the company and its focus. But there are generally a few consistent categories. Figure 1 shows relationships among the various positions as well as possible career paths.

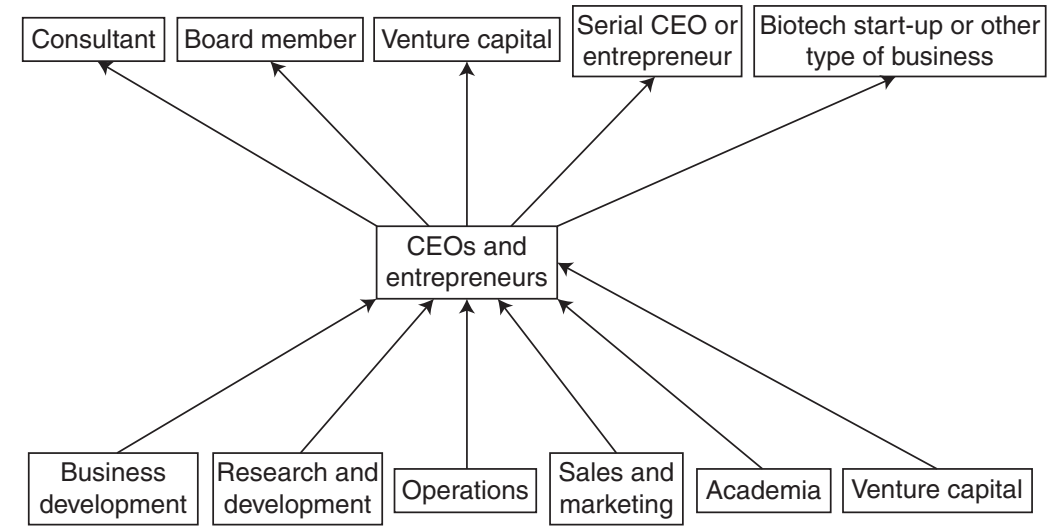

Figure 1. Common career paths for CEOs and entrepreneurs. (Modified, with permission, from Freedman 2008. (C) Cold Spring Harbor Laboratory Press, Cold Spring Harbor, NY.) 
Bench scientists typically work on a variety of projects such as target or assay development, chemical analysis or synthesis, data mining and prediction, instrumentation improvement, or systems optimization. It is more frequently the case that companies hire individuals with very specific subject matter expertise (e.g., microbiomes and obesity) rather than generalized skills (e.g., protein chemistry). In conducting their research, bench scientists may also become involved in analyzing data, publishing results, and filing patents. These activities are often team efforts. With increasing success, the bench scientist will come to make a decision whether to continue at the bench as a senior research scientist or to move into a managerial or leadership position.

Group leaders often assume their positions as a result of taking a leadership role among a small group of researchers working together as a team. The leader assumes responsibility for coordinating the efforts of the team, evaluating results, and assigning specific tasks to be undertaken. They must be experts on data and able to articulate the research findings clearly to senior managers.

Managers and directors expand the scope of responsibility to overseeing the activities of a few groups of research teams. They generally set the goals and expectations of a project or program and track the directions, budgets, and time lines for achievement. They must present data well to senior management and in the context of the business strategy and customer needs and be open to leading individuals through dramatic shifts in project funding or corporate strategy. Beyond hiring and supervising personnel, managers are also responsible for creating an environment that encourages the research groups and supports morale. Often, these individuals have important roles in interfacing with external advisors or scientists, ordepending on the size of the company-speaking to investors. Clearly, in this arena, having strong interpersonal and communication skills, as well as scientific and analytical expertise, becomes increasingly important.

Finally, the top tier of the company is occupied by "C-level" positions, including chief executive officer (CEO), chief financial officer (CFO), and chief scientific officer or chief operating officer (CSO or COO). Responsible for establishing the strategy for the overall direction of the company and reporting to the board of directors, these executives continually develop and revise business plans, engage in fundraising, and respond to general market shifts and demands. In times of success, the company as a whole may be credited, whereas when there are serious problems or even failure, the blame falls primarily on the CEO. Therefore, although considered the "organizing principle" of a company, the CEO can also be a very visible and risky proposition.

\section{Working on Your Own Start-Up: Becoming a Founder}

While working in an academic setting or in a company, you may have an idea that seems worth pursuing as a business venture. We talk more below about various programs and strategies that may help you to assess and carry out the launch of your idea, but here we consider the various stages, roles, and responsibilities of the founder.

The first step is to determine whether the idea is both competitive and fundable. To address this question, it is best to turn to a mentor (a respected professor or supervisor and experienced entrepreneur) for expert and dispassionate advice. With support and encouragement, the next step is to develop a compelling business strategy ("a pitch") to present to possible team members and investors. Consider the following: Do you want to undertake this on your own or enlist the help of a savvy colleague or two? Understand that as a start-up CEO, you will likely have many roles, serving at first as finance and operations officer as well as the primary "human resource." The uniqueness and soundness of the business story ("the special sauce") and your own enthusiasm and sense of vision are critical to raising support for your company. This plan is often presented as a very logical and engaging set of PowerPoint slides that describe in detail to your potential investors how you intend to implement your 


\section{S. Froshauer}

idea and make it profitable (showing how investors will make money). The presentation can serve also as the basis for applying for government support via a small business grant.

Performing proof-of-concept activities serves to validate your business concept. These activities vary with the nature of the business and may include building prototype software, testing marketing hypotheses, continuing biological assays on drugs, developing patents, and accessing key people. The overall goal of your proof of concept is to win the confidence of both investors and potential customers by demonstrating the value and validity of the proposal and its likely outcomes. Often, small sums of money are available from angel investors or the state to support proof-of-concept work.

Acquiring successful capital investment provides the true beginning, enabling you to entice others to join you and begin to form a team that can make your vision a reality. You set the "culture" or style of management of your enterprise to motivate and encourage those whom you have enlisted and to ensure an inspiring and collegial workplace. Your investors may often serve as business advisors or board members to track budget and progress against corporate goals. Creating a scientific advisory board provides the technical balance and expertise to assess and encourage your research activities.

Finally, while working at or establishing a start-up venture can be wonderfully adventurous and rewarding, the day-to-day work may also be challenging and stressful, often demoralizing. The opportunities exist to have a role in many different aspects of the company, sometimes simultaneously. Clearly, these career paths should not be undertaken without careful consideration of what may best suit you personally as well as professionally.

\section{SKILLS/QUALIFICATIONS}

Your graduate and postdoctoral training provide a strong background that enables you to evaluate novel and exciting scientific developments and to envision their possibility for transfer into a business setting. As is true for management positions described in other chapters, the rising executive also requires vision, leadership, and decisiveness - the ability to respond quickly but deliberately to an unexpected changing situation. Similarly, having excellent communication skills, both oral and written, provides a strong advantage. You will need to present your ideas and strategies to a variety of disparate groups. Senior scientists present at team meetings and scientific conferences; managers report to colleagues and to potential investors, and when difficult decisions must be made, managers defend these decisions. Strong analytical and problem-solving skills are necessary features for success. To some degree, many or all these skills come from your experience in pursuing a $\mathrm{PhD}$.

But different abilities and qualifications are also desirable. Typically, a PhD student pursues her/his own research project, collaborating or enlisting help only for specialized parts of the project. Doing research within a company, however, typically involves working - at some level—with or on a team. Thus, the ability to share responsibilities, trust coworkers, and share knowledge and research results is essential. Other expertise needed, usually rarely part of graduate training, is in personnel or financial management. Facility in these areas is important for success in heading an academic research laboratory, as well as in a corporate setting. Any training or courses taken in these areas can only enhance your application for a position.

In terms of self-employment, a sense of ambition, confidence, and passion about your ideas and your company are all essential to promoting your cause. Because you may be called on to deal with any number of questions or problems across the broad spectrum of the business (from science to personnel to workplace operation failures), it is important to be strong-willed, resourceful, and resilienteven optimistic in the face of discouragement. Strategic planning and negotiation skills are indispensable. If you feel that you are lacking in any of these qualifications, consider enlisting a partner (perhaps a business partner) whose expertise complements your own.

A final word on "intellectual honesty": Adherence to the highest ethical standards in 
business practices as well as in personal interactions is absolutely essential to maintain a reputation that serves you and your company well.

\section{GETTING A FOOT IN THE DOOR}

Presenting a resume that reflects a broad range of competencies is a distinct advantage. During your tenure as a $\mathrm{PhD}$ student or postdoctoral fellow, engage in activities that will expand your expertise: Attend and present your results at scientific meetings, plan conferences within your institution, and develop strong writing and communication skills. You will likely have written articles for publication or submitted a research grant (or submitted a section for your advisor's application). To enhance your ability to communicate with the nonscientific sector, consider writing for the university newspaper, explaining recent advances in your department, or starting a student journal. It is also a good idea to take some classes outside of your immediate area of specialization - for example, courses in entrepreneurship, financial management, or business development. Start-ups often have nonpaid internships that flex around graduate or postdoc schedules and offer opportunities to test the culture and contribute to their investor value creation.

The term "networking" has become cliché; however, the value of networking is not to be underestimated. Reach out beyond your immediate (and comfortable) circle of colleagues to become acquainted with those who may serve as mentors or role models. Identify those at your institution who have had some success with inventions, entrepreneurship, and start-up efforts and set up meetings with those individuals. Speak at professional meetings, join local biotechnology associations as well as professional societies, and make use of their career services.

An increasing number of universities and communities now offer entrepreneurial training and support that are well worth exploring. Steve Blank's collaboration with many universities and the National Science Foundation (the I-Corps program) and his Lean Launchpad system provide excellent tools for entrepreneurs (www.steveblank.com). At the University of
Massachusetts, the New Venture Creation Program offers various electives to aspiring entrepreneurs. The Yale Entrepreneurial Institute is devoted to mentoring students with ideas for new ventures, providing expert advice and bringing students together with advisors and consultants. The University of Connecticut houses incubator space and educational programming (the Technology Incubator Program). The Commons in Groton and many other Connecticut accelerator and coworking spaces offer opportunities for local entrepreneurs to connect with mentors and one another and share resources to help develop and expand. The Bioscience ClubhouseCT (www.cureconnect.org) is a state-wide program sponsored by CTNext and Connecticut United for Research Excellence (CURE) to convene students, entrepreneurs, new technology ideas, and start-ups.

\section{CAREER PROGRESSION: THE WAY IN, UP, AND OUT}

If the prospect of beginning your career at a start-up seems a precarious start, it is reasonable first to consider working at a large, better established biotech or pharmaceutical company. There you will learn how research is conducted in a more traditional company setting and, if you seek out opportunities, how business is developed and managed. This early tenure will provide valuable and instructive experience to help you determine how you wish to proceed in your career path and will transfer to and enhance your position should you choose to move to a smaller setting. Working on a research team, whether in a large or small company, will prepare you to continue in research as a senior scientist or project manager and to shift into more managerial positions in the business and operations part of a new venture. Should an opportunity arise, you will have an insider's view, even generally, of how a company is runvaluable training for launching and maintaining your own start-up. Potential investors may view this exposure as value added to a start-up. Progressing from a manager to $\mathrm{CEO}$ or entrepreneur opens the door to a variety of other positions in the corporate world (see 


\section{S. Froshauer}

Fig. 1), serving as consultant or advisor to corporations, universities, and even to state government scientific councils or analysts for venture investors.

It is important to note that entrepreneurs can come out of many different career levels. Many coming from large pharma or biotech companies have created research team projects that enabled them to spin out an idea or technology arising from their own findings when the focus of the company shifted. And, as we have seen, some entrepreneurs come out of academia, forming a company within the university or leaving to form an independent company.

It is also important to be aware that leaving academia for a career in biotechnology is no longer one way only. Success in working in (or starting) a company provides a transition to other related activities in higher education and in government.

\section{BOX 1. My Experience}

My lifelong interest in nature and science came into focus with an opportunity to work, after college, as a research assistant at Cold Spring Harbor Laboratory in New York. Having grown up on Long Island, I was happy to return to a place I knew and to expand my experience in botany into the world of molecular biology.

In the 1970s, Cold Spring Harbor was flooded with scientists pursuing new technology and building new research fields. My passion for scientific excellence, the habit of arduous work hours, and the fun of the exchange of out-in-front, creative ideas began there. This experience led to the pursuit of a doctorate in microbiology and molecular genetics at Harvard and a postdoctoral research fellowship at Yale. After getting my postdoc, I took a position at Pfizer, working first as an antibiotic drug hunter and then as a member of Pfizer's Strategic Alliance Group, formed to execute and manage Pfizer's collaborations with external scientists at biotech or universities. As part of a multidisciplinary team, we were charged with creating a deal (investment) portfolio to access new technology and advance Pfizer's global research strategies.

By 2000, in conversation with a group of like-minded friends and colleagues, we developed an idea for a company that became Rib-X Pharmaceuticals Inc. (now Melinta Therapeutics) in New Haven. Our goal was to design and develop novel antibiotics for the treatment of serious drugresistant infections by exploiting a collective expertise in drug discovery, structural biology, and computational chemistry, in particular, using the structure of the ribosome (for which one of our founders was awarded the Nobel Prize in Chemistry). To support the company, we raised $\sim \$ 160$ million from angels and venture capital investors. After 10 years at Rib-X, I left the company to work with the Yale Entrepreneurial Institute and as Director of the Technology Exchange Portal at University of Connecticut, assisting Connecticut entrepreneurs and others with training programs for students.

My passion for working with entrepreneurs paved the way to my new position as President and CEO of CURE (www.cureconnect.org), a nonprofit organization that serves as an advocate and network for the state's bioscience industry, involving health-related corporations, organizations, associations, and businesses involved in bioscience.

Throughout my career, I have remained involved in my community, serving on many different boards, including the advisory boards of the Yale Entrepreneurial Institute, The Grid (a resource for entrepreneurs around New Haven), UCONN Ventures, and the Angel Investor Forum. I am also a member of the board of the Creative Arts Workshop of New Haven.

My focus is to create research and education partnerships and facilitate collaborations among universities, companies, and investors that promote entrepreneurship and innovation and improve our quality of life. My work with universities and start-ups to identify talent, assess business strategies, and establish a mix of new healthcare-related companies in the state supports this long-term goal. 


\section{BOX 2. Ten Dos and Don'ts}

1. Do spend time formally and informally with a diverse team of mentors up and down the biotechnology food chain. Ask for input on issues arising, pressure testing your own assumptions and leveraging their connections.

2. Do take advantage of local business or entrepreneurial networking and educational forums. Selective, quality, industry-focused conferences can also be valuable.

3. Do learn how to introduce yourself appropriately; offer a business card and share what you do in an engaging manner to identify interesting mentors and connections. Offer a connection or an idea of your own.

4. Do take career risks. Consider joining a company that offers broad opportunities, rather than a larger salary. Move yourself outside of your area of comfortable experience to widen your knowledge and expertise. Appreciate that your first company is a start and not necessarily your destination.

5. Do not forget to serve as an advisor, mentor, or consultant for students, companies, and organizations.

6. Do think more broadly and consider joining a local angel organization, scientific society, or entrepreneurial group that invests in efforts that create community and drive the biotech community.

7. Do stay optimistic and persistent. Optimism is the secret to staying motivated. A new venture will face many challenges but a successful entrepreneur shows persistence in the face of this adversity, keeps focused on the vision, and pushes ahead despite obstacles. To scientists, details are critical and absorbing, but entrepreneurs need to focus on the big picture and avoid becoming distracted.

8. Do remain flexible and adaptable; more than simple perseverance is required. When faced with a serious setback, a successful entrepreneur can adapt the venture to the changed circumstances with a fresh positioning, a different market, a changed business model, a new source of funding, and an alternative technology application-all the while with a clear eye on getting that rock to the top of the hill. Seeking challenging and conflicting inputs from advisors, investors, and colleagues is critical.

9. Do consider a transparent communication style. Investors, colleagues, mentees, and teammates often appreciate knowing your thought process.

10. Do take a step back when you need it. The trick when demoralized is not to force yourself to work but to figure out what it takes to get you back to a state where you want to work. Create a discipline around balancing friends/family and a passion for entrepreneurship.

\section{ADDITIONAL RESOURCES}

Freedman T. 2008. Career opportunities in biotechnology and drug development, pp. 25-32, 311-328. Cold Spring Harbor Laboratory Press, Cold Spring Harbor, NY.

Hill LA, Brandeau G, Truelove E, Lineback K. 2014. Collective genius: The art and practice of leading innovation. Harvard Business Review Press, Boston.

LaMattina JL. 2009. Drug truths: Dispelling the myths about pharmaceutical R\&D. John Wiley \& Sons, Hoboken, NJ.

MIT Technology Review: September/October 2013, 35 Innovators Under 35. http://www.technologyreview.com/ lists/innovators-under-35/2013.
Spors KK. 2009. So, you want to be an entrepreneur. The Wall Street Journal (Journal Reports: Small Business); February 23.

\section{WWW RESOURCES}

www.cureconnect.org Connecticut United for Research Excellence.

SteveBlank.com/2013/08/21/reinventing-life-sciencestartups-evidence-based-entrepreneurship-2/ 


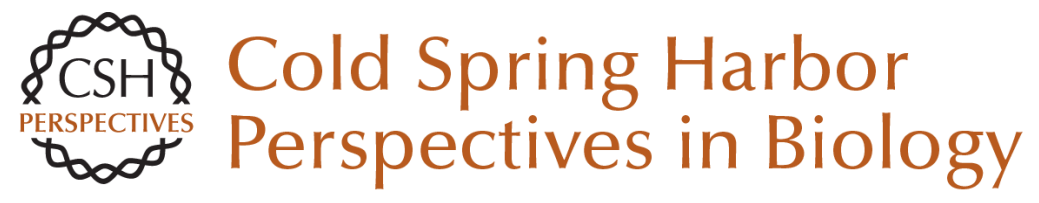

\section{Careers at Biotech Start-Ups and in Entrepreneurship}

Susan Froshauer

Cold Spring Harb Perspect Biol 2017; doi: 10.1101/cshperspect.a032938

\section{Subject Collection Career Options for Biomedical Scientists}

\section{Careers in Science Publishing} John R. Inglis

Medical Communications: The "Write" Career

Path for You? Yfke Hager

At the Crossroads of Science and Society: Careers in Science Policy Amy P. Patterson, Mary E. Groesch, Allan C. Shipp, et al.

A Career in Patent Law: At the Cutting Edge of Science, but Not at the Bench Salim Mamajiwalla

Careers in Science and Grant Administration: View from the National Institutes of Health Marion Zatz and Sherry Dupere

Careers at Biotech Start-Ups and in

Entrepreneurship Susan Froshauer

Careers in Science Journalism and Writing Helen Pearson

\author{
Careers in Academic Administration \\ Lydia Villa-Komaroff \\ Working for a Scientific Society \\ Martin Frank
A Career for Life Scientists in Management Consulting Rodney W. Zemmel \\ Careers in Core Facility Management \\ Claire M. Brown \\ Leaving the Bench and Finding Your Foundation \\ John E. Spiro
A Career at a Small Liberal Arts College Jennifer Punt \\ Career Options for Scientists \\ Richard Sever and Kaaren Janssen
}

For additional articles in this collection, see http://cshperspectives.cshlp.org/cgi/collection/

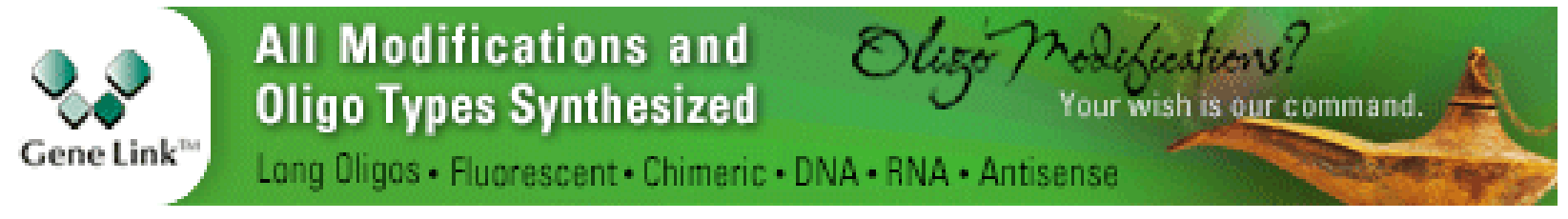

